\title{
Awareness, Intention to Act and Action in the Exercising of Patients' Rights: A Case Study of Patients in Khmer Soviet Friendship Hospital, Phnom Penh, Cambodia
}

This article was published in the following Dove Press journal:

Risk Management and Healthcare Policy

\author{
Borey Ban (1) 1,2 \\ Tipaporn Kanjanarach $\mathbb{D}^{3}$ \\ Sutin Chanaboon ${ }^{4}$ \\ 'Technical School for Medical Care, \\ University of Health Sciences, Phnom \\ Penh, Cambodia; ${ }^{2}$ Faculty of \\ Pharmaceutical Sciences, Khon Kaen \\ University, Khon Kaen 40002, Thailand; \\ ${ }^{3}$ Department of Social and Administrative \\ Pharmacy and Center for Research and \\ Development of Herbal Health Product, \\ Faculty of Pharmaceutical Sciences, Khon \\ Kaen University, Khon Kaen 40002, \\ Thailand; ${ }^{4}$ Department of Community \\ Health, Sirindhorn College of Public \\ Health Khon Kaen, Khon Kaen 40000, \\ Thailand
}

Background and Objectives: In Cambodia, the patients' rights guideline was officially released in 2007 as a measure of the government policy to promote greater awareness and empower Cambodian people to exercise their rights as patients. The aim of this study was to identify the proportion of patients aware of the existence of patients' rights and compare the proportions of patients intending to exercise their rights and those actually exercising their rights among the aware and unaware groups.

Methods: Data were collected with a structured questionnaire, using face-to-face interview technique, from 142 randomly selected outpatients visiting the Khmer Soviet Friendship Hospital in Phnom Penh, Cambodia. Intention to exercise patients' rights was measured on a 5-point Likert scale (ranging from 1 "definitely not" to 5 "definitely yes").

Results: The proportion of Cambodian patients who were aware of the existence of patients' rights was $31.0 \%(95 \% \mathrm{CI}: 23.5,39.3)$. The average intention to act scores was $4.0 \pm 0.5$ for the whole group, and $4.3 \pm 0.4$ and $3.9 \pm 0.5$ for those aware and unaware of the existence of patients' rights, respectively. The difference in the mean scores of intentions to act between the aware and unaware groups was statistically significant (mean difference $=0.40,95 \% \mathrm{CI}$ : $0.22,0.58, \mathrm{t}_{140}=4.514, \mathrm{P}<0.001$ ). Patients reported a total of 250 situations in which they believed they should take action to exercise their rights and 96 times that they took action (38.4\%, 95\% CI: 35.46, 41.34).

Conclusion: The proportion of Cambodian outpatients aware of the existence of patients' rights and the proportion of outpatients that exercised their rights were both low. Nevertheless, it appeared that raising awareness of the existence of patients' rights raised patient's intention to act, which corresponds to the hierarchy-of-effects behavioral model.

Keywords: patients' rights, human rights, equality, confidentiality, privacy, health care services

\section{Introduction}

As expressed in the Universal Declaration of Human Rights in 1948, it is recognized that all human beings are entitled to dignity and equality. ${ }^{1}$ Since then, patients' rights have been recognized as one of the basic rights of humans. Although the concept of patients' rights is universal, the implementation has been different in each country to suit the country's cultural and social norms and has occurred at different times. Several countries have implemented patients' rights as
Correspondence: Tipaporn Kanjanarach Department of Social and Administrative Development of Herbal Health Product. Faculty of Pharmaceutical Sciences, Khon Kaen University, Khon Kaen 40002, Thailand

Tel +66817392822

$\mathrm{Fax}+66043202379$

Email otipkan@kku.ac.th
Risk Management and Healthcare Policy 2020:I3 2365-2370

mit your manuscript (c) (i) 2020 Ban et al. This work is published and licensed by Dove Medical Press Limited. The full terms of this license are available at https://www.dovepress.com/terms.php cc) ${ }_{\mathrm{BY}} \mathrm{NC}_{\text {and }}$ ancorporate the Creative Commons Attribution - Non Commercial (unported, v3.0) License (http://creativecommons.org/licenses/by-nc/3.0/). By accessing the work you hereby accept the Terms. Non-commercial uses of the work are permitted without any further permission from Dove Medical Press Limited, provided the work is properly attributed. For permission for commercial use of this work, please see paragraphs 4.2 and 5 of our Terms (https://www.dovepress.com/terms.php). 
law while others have only used guidelines. For example, the US implemented the first patients' rights bill in $1973 .^{2}$ Developing countries were later to introduce patients' rights, Egypt implemented their patients' rights in 2005 and Sudan in 2009. ${ }^{3,4}$

In Cambodia, like other developing countries, patients' rights have only recently been implemented. The Cambodian national standard of patients' rights package contained two sets of guidelines, one for clients or patients which is called Clients' Rights and the other for healthcare providers which is called Providers' Rights-Duties. This package was created in 2004, officially endorsed by Ministry of Health of Cambodia on 31st August 2006 and delivered in 2007. The guideline for providers focuses on promoting changes in attitude and behavior of health personnel to deliver more effective health service. The guideline for patients included 22 key concepts of patient rights, eight were related to outpatients: 1) The right to equality 2) The right to access information. 3) The right to be respected for culture and value. 4) The right to confidentiality. 5) The right to privacy. 6) The right to choose and change physicians. 7) The right to refuse intervention. 8) The right to express opinion. ${ }^{5}$ The guideline for patients is intended to be used as a tool to promote awareness and empower Cambodian people to exercise their rights.

The hierarchy-of-effects model (HOEM) is a model commonly used in business to study people's behavior after they are exposed to a new campaign or advertisement. According to the HOEM, the process to understand the message is developed first, then the attitude toward the behavior and the intention to execute the behavior are formed and finally the behavior is performed. ${ }^{6,7}$ The HOEM has been applied to explain the effect of public health campaigns since $1980 .^{8,9}$ The HOEM may be used to explain the hierarchy of processes and outcomes following exposure to the campaign about patients' rights launched by the government. After patients are exposed to the campaign, they should become more aware of the existence of patients' rights and start to understand the key concepts of patients' rights and know their responsibilities. The process should help patients to form the intention to take action when they face situations in which their rights must be protected and support them to take action when they actually confront the situation.

From our review, previous reports of the outcomes of patient's rights campaigns in Cambodia have not been found. Furthermore, the proportion of Cambodian patients exposed to this campaign is not known. We hypothesized that patients who were aware of the existence of patients' rights would have a higher degree of intention to exercise their right than those who were unaware. Therefore, this study aimed to identify the proportions of patients who were aware and unaware of the existence of patients' rights, compare the intention to exercise patients' rights between the aware and unaware groups, and finally determine the proportion of times that action was taken by these groups to protect their rights. This study focused on the eight key concepts of rights related to outpatients.

\section{Materials and Methods}

This quantitative survey protocol was approved by the National Ethics Committee for Health Research of Cambodia (NECHR No 212) and by the Khon Kaen University Ethics Committee in Human Research (HE 622187). This study was conducted in accordance with the Declaration of Helsinki.

The studied sample was Cambodian outpatients visiting Khmer Soviet Friendship Hospital (KSFH) in Phnom Penh, Cambodia during August-October 2019. The inclusion criteria were; age from 18 years to 65 years, did not have mental problems, visited the hospital within the last three months, agreed to participate by signing the consent form and could communicate in Khmer language. The exclusion criteria were subjects who needed emergency attention or declined to participate.

The sample size was estimated using the formula to estimate the interested proportion among an infinite population. ${ }^{10}$ The proportion of the population aware of the patient's rights guideline was estimated to be 0.36 , based on a previous study. ${ }^{11}$ The error of estimation was set to be $10 \%$. The minimum number of subjects needed was 89 , which was doubled to 178 as it was estimated that approximately $50 \%$ of patients would have visited the hospital in the last three months. Profiles of patients waiting in front of the outpatient department were randomly selected. After the patient agreed to participate and signed a consent form, the researcher read the self-developed structured questionnaire to the patients and helped to fill in the question for the subjects. This method was chosen because most subjects could not read well. At the completion of data collection, 142 patients were recruited. The questionnaire was assessed for face validity by three experts, each with more than five years' experience in health consumer protection and questionnaire development. 
The questionnaire was divided into two parts, (1) sociodemographic data and (2) awareness of the existence of patients' rights and the expected outcome of the campaign. Awareness was measured by the question "Do laws/regulations/guidelines to protect and promote patients' rights exist in Cambodia?" and the response options were "yes" and "no" and "not sure". Awareness was triangulated by the questions "In your opinion, what are patients' rights?" and "Could you please give me a few examples of patients' rights?"

Eight if-clause statements and questions (starting with "In the future, if you ... (scenario), will you ... (take action)?") were asked to assess subjects' intention to act. The response options were a 5-point Likert scale ranging from [1] Definitely not, [2] Likely to be not, [3] Not sure, [4] Likely to be yes, [5] Definitely yes. To assess subjects' experience in taking action to protect their rights, patients were presented 8 situations depicting patients' rights. Patients who responded that they had experienced a situation were then asked whether they took any action to protect their rights. The response options were "yes" and "no".

\section{Results}

\section{Socio-Demographic Data}

In this study, the majority of subjects were female (66.2\%). The average age of the sample group was 39.1 \pm 12.1 years. Most of the subjects had a secondary school level education or lower (64.8\%) and were in the bluecollar occupation group, e.g. agricultural workers, construction workers, and industrial workers (56.3\%). Details of the socio-demographic data of the subjects are shown in Table 1.

\section{Awareness of the Existence of Patients' Rights and Intention to Exercise Their Rights}

Of the 142 subjects interviewed, 44 reported that they were aware of the existence of patients' rights, yielding the proportion of patients who were aware of the existence

Table I Socio-Demographic Data of the Sample $(n=\mid 42)$

\begin{tabular}{|l|l|l|}
\hline Socio-Demographic Data & Frequency & Percentage \\
\hline Gender: Female & 94 & 66.2 \\
Education: S Secondary school & 92 & 64.8 \\
Occupation: Blue-collar group & 80 & 56.3 \\
Reason for current visit: Chronic disease & 64 & 45.1 \\
Acute disease, minor surgery & 78 & 54.9 \\
\hline
\end{tabular}

of patients' rights to be $31.0 \%$ (95\% CI: $23.5,39.3)$. The majority of subjects reported that they had the intention to exercise their rights if in the future they faced situations that required them to exercise their rights, for all eight key concepts of the patients' rights guideline (Table 2).

The average scores from the 5-point Likert scale of intention to act were $4.0 \pm 0.5$ for the whole group, and 4.3 \pm 0.4 and $3.9 \pm 0.5$ for the groups that were aware and unaware of the existence of patients' rights, respectively. The difference in the mean scores of intention to act between the aware and unaware groups was 0.40 (95\% CI of the difference $0.22,0.58$ ), which was statistically significant $(\mathrm{t}=4.514, \mathrm{df}=140, \mathrm{P}<0.001)$.

\section{Action Taken to Protect Patients' Rights}

Of 142 subjects, 114 reported that they experienced at least one of the eight situations depicting patients' rights. The 142 subjects reported In total, there were 250 instances where subjects had experienced the situations that infringed on their rights as a patient and 96 times that they took action, yielding the proportion of action taken to protect patients' rights to be 38.4 percent (95\% CI: $35.46,41.34)$.

\section{Discussion}

The $31 \%$ of Cambodian patients who were aware of the existence of patients' rights in this study were similar to that found in Pakistan where $36 \%$ of the patients were aware of their rights. ${ }^{11}$ It was also higher than in previous studies in Egypt where only 24\% of patients were aware of their own rights and in Saudi Arabia where $21.9 \%$ knew about the existence of the patients' bill of rights. ${ }^{3,12}$ A study in Sudan found only $4.8 \%$ of subjects knew about the patients' rights bill in their country and the authors proposed that the low rate of awareness was likely due to a lack in the distribution of patients' rights information. ${ }^{4} \mathrm{~A}$ study conducted in Iran also found a low rate of awareness of patients' rights and that most patients had not seen the Iranian patients' rights bill. ${ }^{13}$ A similar lack of patients' rights information coupled with the low educational level of many Cambodian patients could contribute to the low rate of awareness found in our study as patients may have difficulty in comprehending medical related matter. Hence, in Cambodia, information on patients' rights should be disseminated via mass media such as in a campaign on radio or on television rather than via printed materials such as posters or brochures. 
Table 2 Intention to Exercise Patients' Rights

\begin{tabular}{|c|c|c|c|c|}
\hline \multirow[t]{2}{*}{ Right to } & \multirow[t]{2}{*}{ Statement } & \multicolumn{3}{|c|}{$\begin{array}{l}\text { Having Intention to Take Action * } \\
\text { n (\%) }\end{array}$} \\
\hline & & $\begin{array}{l}\text { Total } \\
(n=\mid 42)\end{array}$ & $\begin{array}{l}\text { Aware } \\
\text { group } \\
(n=44)\end{array}$ & $\begin{array}{l}\text { Unaware } \\
\text { group } \\
(n=98)\end{array}$ \\
\hline I. Equality & $\begin{array}{l}\text { If you are in a queue waiting for a physician and someone steps out of the line, } \\
\text { will you come forward to deal with that problem? }\end{array}$ & $109(76.8)$ & $38(86.4)$ & $7 \mid(7 \mid .4)$ \\
\hline $\begin{array}{l}\text { 2. Access } \\
\text { information }\end{array}$ & $\begin{array}{l}\text { If you are not informed about your health status; will you ask for that } \\
\text { information from the health care provider? }\end{array}$ & I 38 (97.2) & $43(97.7)$ & $95(96.9)$ \\
\hline $\begin{array}{l}\text { 3. Be respected for } \\
\text { culture and values }\end{array}$ & $\begin{array}{l}\text { If a health care provider gives medical treatment or procedures that are } \\
\text { contrary to your culture or values, will you refuse that treatment? }\end{array}$ & III (78.9) & $41(93.2)$ & 7I (7I.4) \\
\hline 4. Confidentiality & $\begin{array}{l}\text { If you are worried about the confidentiality of your health status, medical } \\
\text { condition, etc., will you ask the health care provider for clarification? }\end{array}$ & I0I (7I.I) & $38(86.4)$ & $63(64.2)$ \\
\hline 5. Privacy & $\begin{array}{l}\text { If you are worried about your privacy regarding your physical examination and } \\
\text { treatment, will you request that the health care provider ensures your privacy? }\end{array}$ & II4 (80.3) & $42(95.4)$ & $72(73.5)$ \\
\hline $\begin{array}{l}\text { 6. Choose and } \\
\text { change their } \\
\text { physician }\end{array}$ & $\begin{array}{l}\text { If you want to seek advice from a particular doctor, will you request to meet } \\
\text { her/him? }\end{array}$ & 122 (85.9) & $39(88.6)$ & $83(84.7)$ \\
\hline $\begin{array}{l}\text { 7. Refuse } \\
\text { intervention }\end{array}$ & $\begin{array}{l}\text { If you are given a medical treatment or procedure that you think you do not } \\
\text { need, will you refuse that treatment? }\end{array}$ & $97(68.3)$ & $35(79.5)$ & $62(63.2)$ \\
\hline 8. Express opinion & $\begin{array}{l}\text { If you want to express your opinion regarding health care services, will you do } \\
\text { so? }\end{array}$ & $142(100.0)$ & $44(100.0)$ & $98(100.0)$ \\
\hline
\end{tabular}

Note: *Answer "Yes" or "Definitely yes" to the scenario statement.

In this study, a positive association between having awareness of the existence of patients' rights and forming the intention to act was found. It should be noted that being unaware of the existence of the patients' rights guideline did not preclude patients from knowing their rights. However, knowing that the guideline existed appeared to raise patients' intention to exercise their rights when using healthcare services. In this study, we also asked patients about their experience of taking action to protect their rights when faced with a situation where they should exercise their rights. Overall, patients took action in approximately one-third of the situations where they should exercise their rights. When looking into differences in intention to take action between the aware and the unaware groups according to the eight key concepts of patients' rights being studied, the largest differences were in the rights to confidentiality, to privacy and to refuse intervention. We also found that the rates of patients' experience of taking action to protect their confidentiality, privacy and to refuse intervention were also low (Table 3). In Cambodia, there is a perceived unequal status between healthcare providers and patients that may contribute to this low rate. In pain management, for example, patients' feelings of inferiority to their healthcare provider have caused them to feel uncomfortable about asking the doctor for information and reluctant to participate in their treatment decisions. ${ }^{14}$ In our study, it is possible that patients may feel that they do not have sufficient knowledge about their medical procedures and let the healthcare providers have full authority to make decisions about interventions. The perceived unequal status also discourages patients from requesting privacy during examinations or requesting that their information be kept confidential. It is also possible that patients misunderstood the difference between revealing necessary information for diagnosis and the disclosing of patients' information by healthcare providers. Therefore, health facilities should emphasize the high responsibilities of healthcare providers in patients' data sharing. A study in Jordan found that the practices of healthcare providers in medical data confidentiality were less than optimal and could lead to the loss of patients' trust in healthcare 
Table 3 Proportion of Subjects Who Experienced Situations in Which They Could Exercise Their Patient Rights and Those Who Took Action

\begin{tabular}{|c|c|c|c|c|c|}
\hline \multirow[t]{2}{*}{ Right to } & \multirow[t]{2}{*}{ Situation } & \multicolumn{2}{|c|}{ Experience\# } & \multicolumn{2}{|c|}{$\begin{array}{l}\text { Taking } \\
\text { Action* }\end{array}$} \\
\hline & & $\mathbf{n}$ & (\%) & $\mathbf{n}$ & (\%) \\
\hline I. Equality & You suspected that patients who came later than you received services before you. & 23 & $(16.2)$ & 7 & $(30.4)$ \\
\hline 2. Access information & $\begin{array}{l}\text { You were not informed about your health status, diagnosis, results of examinations, } \\
\text { potential risks or benefits of each procedure. }\end{array}$ & 50 & $(35.2)$ & 27 & $(54.0)$ \\
\hline $\begin{array}{l}\text { 3. Be respected for } \\
\text { culture and values }\end{array}$ & You were recommended treatment that is against your culture or values. & 31 & $(21.8)$ & 9 & $(29.0)$ \\
\hline 4. Confidentiality & $\begin{array}{l}\text { You suspected that information about your health status may be disclosed to others } \\
\text { without your permission. }\end{array}$ & 18 & $(12.7)$ & 2 & $(11.1)$ \\
\hline 5. Privacy & $\begin{array}{l}\text { You suspected that the results of your physical examination and treatment were not } \\
\text { being kept private. }\end{array}$ & 10 & $(7.0)$ & 2 & $(20.0)$ \\
\hline $\begin{array}{l}\text { 6. Choose and change } \\
\text { their physician }\end{array}$ & You felt uncomfortable to see a particular physician. & 32 & $(22.5)$ & 13 & $(40.6)$ \\
\hline 7. Refuse intervention & $\begin{array}{l}\text { You were ordered to undergo medical treatment or procedures that you think you do } \\
\text { not need and wanted to refuse. }\end{array}$ & 9 & $(6.3)$ & 2 & $(22.2)$ \\
\hline 8. Express opinion & $\begin{array}{l}\text { You felt unhappy with the health care service and wanted to complain or express your } \\
\text { opinion. }\end{array}$ & 77 & $(54.2)$ & 34 & $(44.1)$ \\
\hline
\end{tabular}

Notes: $\# \%$ having experience $=($ number of subjects reported having experience/ 142$) \times 100 . \%$ taking action $=($ number of subjects taking action/number of subjects having experience) $\times 100$.

providers. ${ }^{15}$ At the same time, strategies to raise patients' intention to protect their confidentiality and privacy should be identified. When discussing medical interventions with patients, healthcare providers should take an information provider role and encourage patients to take part in the decision-making. In this study, the strength of the association between the intention to act and action could not be estimated with certainty due to the small sample size. However, while the rate of intention to act in the future was high, the rate of action in the past was low. One explanation would be that patients have learnt the negative consequences of not exercising their rights; therefore, the have formed the intention to protect their rights if they face that problem again in the future. Several health behaviors studies have found that not all intention turns into behavior. The degree to which intention to act turns into action depends on the presence or absence of barriers or facilitating factors. ${ }^{16}$ Placing signs outlining patients' rights in health facilities would help create an environment that facilitates patients to exercise their rights.

One of the limitations of this study was subject recruitment. While an attempt was made to minimize selection bias by employing a random selection technique, the demographic data show far more female participants than male. This finding is similar to previous hospital survey studies that show a majority of their sample were female. ${ }^{4,17,18}$ One possible explanation is that females visit hospitals more than males. This suggests that there may be an unavoidable gender bias in hospital survey studies. In the future, differences between male and female patients in the awareness of and intention to exercise patients' rights should be explored.

\section{Conclusion}

Patients' rights are a significant component of healthcare practice. They are used as a tool for patients to safeguard their own health and to promote ethical medical practice. While other authors have produced similar studies about patient rights, this study is novel in Southeast Asia and adds to the body of work indicating that patients' rights are not being adequately addressed in low- and middle-income countries around the world.

Based on our findings, it seems that although there are policies to promote patients' rights that have been in effect for more than ten years, the proportion of Cambodian 
patients who are aware of the existence of patients' rights in their own country is low. Furthermore, the proportion of apposite events in which outpatients exercised their rights was low. Our results provide some support for the HOEM behavioral model in that awareness of the existence of patients' rights appeared to raise the intention to act.

\section{Acknowledgments}

The funding of this study was supported by the Thailand International Cooperation Agency (TICA) and the Faculty of Pharmaceutical Sciences of Khon Kaen University. The authors would also like to thank Dr Glenn Borlace, Faculty of Pharmaceutical Sciences of Khon Kaen University, for editing English grammar and special thanks to KSFH staff and patients for their collaboration in this study.

\section{Disclosure}

The authors report no conflicts of interest in this work.

\section{References}

1. WHO. Genomic resource centre: patients' rights. www.who.int/geno mics/public/patientrights/en/. Accessed September 10, 2018.

2. American Patient Rights Association. AHA Patient's bill of rights. www. americanpatient.org/aha-patients-bill-of-rights/. Accessed September 12, 2018.

3. Mohammed ES, Seedhom AE, Ghazawy ER. Awareness and practice of patient rights from a patient perspective: an insight from Upper Egypt†. Int J Qual Health Care. 2018;30(2):145-151. doi:10.1093/ intqhe/mzx 182

4. Younis AA, Hassan AH, Dmyatti EM, et al. Awareness and practice of patients' rights among hospitalized patients at Wad-Medani Teaching Hospital, Sudan. East Mediterr Health J. 2017;23(2):80-86.

5. Ministry of Health of Cambodia. Operational guidelines for clients' rights and providers' rights-duties. 2007:1-19.
6. Barry TE. The development of the hierarchy of effects: an historical perspective. J Curr Issues Res Advert. 1987;10(1-2):251-295.

7. Bauman A, Bowles HR, Huhman M, et al. Testing a hierarchy-ofeffects model: pathways from awareness to outcomes in the VERB ${ }^{\mathrm{TM}}$ campaign 2002-2003. Am J Prev Med. 2008;34(6S):S249-S256.

8. McGuire WJ. Public communication as a strategy for inducing health-promoting behavioral change. Prev Med. 1984;13:299-319.

9. Kite J, Gale J, Grunseit A, Li V, Bellew W, Bauman A. From awareness to behaviour: testing a hierarchy of effects model on the Australian Make Healthy Normal campaign using mediation analysis. Prev Med Rep. 2018;12:140-147.

10. Hsieh F, Bloch D, Larsen M. A simple method of sample size calculation for linear and logistic regression. Statist Med. 1998;17 (14):1623-1634. doi:10.1002/(SICI)1097-0258(19980730)17:14<16 23::AID-SIM871>3.0.CO;2-S

11. Tabassum T, Ashraf M, Thaver I. Hospitalized patients' awareness of their rights-a cross-sectional survey in a public and private tertiary care hospitals of Punjab, Pakistan. J Ayub Med Coll Abbottabad. 2016;28(3):582-586.

12. Alghanim SA. Assessing knowledge of the patient bill of rights in central Saudi Arabia: a survey of primary health care providers and recipients. Ann Saudi Med. 2012;32(2):151-155. doi:10.5144/02564947.2012.151

13. Davati A, Seidmortaz S, Zafarghandi N, Azimi A, Arbab Solimani S. An assessment of Tehran graduated general physicians' knowledge about the charter of patients' rights. Int Res J. 2012;3(4):357-361.

14. McQuay H. Acute Pain Management. Cambridge University Press; 2009.

15. Karasneh RA, Al-Azzam SI, Alzoubi KH, Hawamdeh SS, Muflih SM. $<\mathrm{p}>$ Patient Data Sharing and Confidentiality Practices of Researchers in Jordan. <![CDATA[Risk Management and Healthcare Policy]]>. 2019;12:255-263. doi:10.2147/RMHP.S22 7759

16. Ajzen I. The theory of planned behavior. Organ Behav Hum Decis Process. 1991;50(2):179-211.

17. Mahrous MS. Patient's bill of rights: is it a challenge for quality health care in Saudi Arabia? Saudi J Med Med Sci. 2017;5 (3):254-259. doi:10.4103/sjmms.sjmms_147_16

18. Kagoya HR, Kibuule D, Mitonga-Kabwebwe H, Ekirapa-Kiracho E, Ssempebwa JC. Awareness of, responsiveness to and practice of patients' rights at Uganda's national referral hospital. Afr J Prm Health Care Fam Med. 2013;5(1):1-7.
Risk Management and Healthcare Policy

\section{Publish your work in this journal}

Risk Management and Healthcare Policy is an international, peerreviewed, open access journal focusing on all aspects of public health, policy, and preventative measures to promote good health and improve morbidity and mortality in the population. The journal welcomes submitted papers covering original research, basic science, clinical \& epidemiological studies, reviews and evaluations, guidelines, expert opinion and commentary, case reports and extended reports. The manuscript management system is completely online and includes a very quick and fair peer-review system, which is all easy to use. Visit http://www.dovepress.com/testimonials.php to read real quotes from published authors. 